\title{
A cooperação científica internacional na Amazônia
}

\author{
WILLIAM GAMA e LÉA VELHO
}

\section{Introdução}

A COOPERAÇÃo internacional em ciência e tecnologia tem crescido a uma taxa significativa. Partindo de uma base inexpressiva em meados do século XX, a cooperação internacional representa hoje uma parcela considerável da pesquisa científica. Quando medida, por exemplo, através da contagem de artigos publicados em co-autoria por pesquisadores trabalhando em, pelo menos, dois países diferentes, a cooperação internacional mais do que duplicou entre 1988 e 2001 - passou de 8 para 18\% do total de artigos publicados e indexados pelo Science Citation Index (NSF, 2004, Science and Engineering Indicators, pp. 5-44).

Esse crescimento, no entanto, afetou de maneira desigual tanto as diversas áreas de conhecimento como os diferentes países. Por razões óbvias, a explosão das chamadas parcerias em pesquisa e desenvolvimento é muito mais comum entre países avançados. Entretanto, em algumas áreas de conhecimento e atividades, o envolvimento de países em desenvolvimento torna-se fundamental para o avanço do conhecimento. Esse é tipicamente o caso dos estudos de biodiversidade e das suas aplicações tecnológicas e econômicas. A razão simples é que os recursos genéticos ainda desconhecidos e inexplorados concentram-se nos países em desenvolvimento. Nesse quesito, destaca-se a Amazônia e, conseqüentemente, o Brasil, onde se localiza a maior parte dessa floresta.

O interesse internacional sobre a Amazônia é bastante antigo, e as expedições científicas estrangeiras para coleta de material e posterior classificação e análise datam de centenas de anos. Entretanto, nas últimas décadas, particularmente com o advento da biotecnologia moderna, que abriu a possibilidade de novas aplicações tecnológicas, os recursos genéticos presentes na Amazônia passaram a ter uma importância estratégica. Isso, ao mesmo tempo em que estimulou o interesse internacional no estudo e na coleta da biodiversidade local, colocou um desafio ao país, qual seja, como garantir a participação brasileira no conhecimento gerado sobre a floresta, seus recursos e suas aplicações?

Esse desafio torna-se particularmente urgente porque se sabe que o estudo da biodiversidade amazônica não é possível sem a cooperação internacional. A exigência em termos de recursos financeiros, humanos e materiais para esta tarefa é de tal dimensão, que é impossível, além de indesejável, que o Brasil possa realizá-la isoladamente. De fato, há muito tempo o país já admitiu que necessita 
da cooperação internacional e abriu as portas das mais importantes instituições de pesquisa da região para abrigar cientistas estrangeiros. Entretanto, foi apenas na última década, exatamente pela importância estratégica atribuída à biodiversidade, que surgiu a preocupação, por parte de estudiosos e organizações, de avaliar os impactos da cooperação internacional na Amazônia tanto na atividade de pesquisa, como em outros setores, incluindo possíveis benefícios para a população local.

Os estudos de avaliação revelaram um quadro pouco animador. Ficou claro, por exemplo, que as relações que se estabelecem são assimétricas, com uma dominação dos parceiros estrangeiros em termos do controle da agenda de pesquisa, recursos disponíveis e apropriação dos resultados gerados, principalmente no que diz respeito a publicações. Além disso, evidenciou-se que os programas de cooperação internacional têm pouca convergência com os objetivos estratégicos dos centros de pesquisa regionais e estão ainda mais distantes das demandas e necessidades de desenvolvimento das populações locais.

Algumas razões para esse estado de coisas foram apontadas. Por um lado, as dificuldades financeiras enfrentadas pelas instituições locais, assim como a falta de capacitação científica das mesmas, colocam-nas em uma posição frágil na mesa de negociação. Assim, tais instituições entram em parcerias sem que estejam devidamente preparadas para saber o que desejam, mas suficientemente ávidas por recursos financeiros para aceitar o que lhes for oferecido (Velho, 1994; Canto, 2003). Por outro lado, parece existir uma enorme falha institucional do estado brasileiro em termos do controle e monitoração da cooperação internacional na Amazônia, de forma a atender os interesses nacionais (Becker, 2003).

É verdade que, desde 1933, o governo brasileiro dispõe de legislação e regulamentos para viabilizar o controle e a fiscalização da pesquisa científica estrangeira isolada (expedições científicas) em território nacional. Essa legislação, que já sofreu uma série de mudanças ao longo dos anos, em essência, busca garantir a participação de cientistas brasileiros nos projetos de pesquisa estrangeiros e se propõe a controlar a saída indiscriminada de material de interesse científico coletado no Brasil, entre outras coisas. Entretanto, nunca houve um acompanhamento sistemático da implementação do regulamento vigente, de tal forma que as normas eram apenas nominalmente cumpridas.

O parco controle do Estado sobre os programas de cooperação internacional na Amazônia parece ter se agravado ainda mais com a última mudança na legislação, datada de 15/1/1990. Trata-se da portaria 55/90 do Ministério da Ciência e Tecnologia que concedeu "tratamento especial" a pesquisadores estrangeiros vinculados a acordos de cooperação internacional. A partir de então, instituições e pesquisadores estrangeiros podem realizar coleta de dados e materiais científicos no Brasil sem ter que se submeter, como antes, às exigências impostas pelo Ministério de Ciência e Tecnologia ${ }^{1}$.

Este artigo busca entender algumas das circunstâncias que podem ter levado à situação descrita acima relativa à cooperação internacional, tendo como 
foco o Instituto Nacional de Pesquisas da Amazônia (Inpa), um dos institutos governamentais de pesquisa mais antigos da região e que concentra, por meio de seus convênios, grande parte da pesquisa científica estrangeira na região. A hipótese aqui aventada é a de que o novo mecanismo de "convênios de cooperação internacional", criado, entre outras razões, para solucionar problemas identificados na implementação das "expedições científicas", em vez de resolver os problemas anteriores, tornaram-nos ainda mais graves.

Mais especificamente, este artigo limitar-se-á a analisar parte dessa questão complexa, qual seja, a política de cooperação científica internacional no Inpa. Para tanto, serão apresentadas e discutidas as diversas visões existentes sobre essa cooperação, incluindo aquelas oriundas de analistas externos ao Inpa, assim como as do pessoal do próprio instituto. O objetivo central é apontar as convergências e sistematizar pontos e questões que necessitam de ação imediata para que a cooperação científica internacional venha a gerar benefícios para a ciência nacional e para o desenvolvimento da região.

\section{O Inpa}

O Inpa foi criado em 1952 como uma resposta do governo brasileiro à opinião pública internacional, em função do veto do Congresso Nacional brasileiro à criação de um instituto similar, só que de caráter internacional, que se organizava naquela época em torno da recém-criada Unesco. O estatuto do Inpa colocava-o como fonte de afirmação da soberania nacional no direcionamento e controle da pesquisa científica brasileira na Amazônia.

O Instituto foi instalado em 1954 no ponto central da Amazônia brasileira, em Manaus (AM). Ficou subordinado ao Conselho Nacional de Desenvolvimento Científico e Tecnológico $(\mathrm{CNPq})$, também recém-criado, onde permaneceu até 1987 , ocasião em que, com a criação do MCT, foi transferido para aquele órgão, onde está até hoje. Possui atualmente 775 servidores na ativa e 169 aposentados, além de 322 bolsistas. Do quadro total, 213 são pesquisadores ( 23 estrangeiros), sendo 140 doutores, 61 mestres e quatro graduados (site do Inpa, acesso 15/1/2005). Além desses, cerca de cem pesquisadores e estudantes estrangeiros circulam diariamente pelo Inpa ligados a projetos de cooperação bilateral e multilateral.

O Inpa tem sua sede em uma área de $379.868,41 \mathrm{~m}^{2}$, na parte urbana de Manaus, distribuída em três campi Urbanos. Além disso, possui três reservas florestais e duas biológicas, quatro estações experimentais, duas bases flutuantes de pesquisa, um laboratório flutuante e um barco de pesquisa.

No início, o Inpa teve grandes dificuldades para se estruturar devido à falta de recursos humanos e materiais ${ }^{2}$. No final da década de 1960 e início da de 1970, quando o governo militar iniciou a construção de grandes estradas, hidrelétricas e projetos mínero-metalúrgicos na região amazônica, o Inpa obteve grande impulso com a construção de seu campus principal, com cerca de quarenta prédios e mais de uma centena de laboratórios. Possui atualmente algumas coleções, o 
maior herbário da Amazônia, bibliotecas, reservas florestais (Amazonas e Rondônia) e núcleos de pesquisas em Rio Branco (AC) e Boa Vista (RR).

O instituto está organizado em onze coordenações de pesquisas (biologia aquática, aqüicultura, ecologia, ciências da saúde, produtos naturais, tecnologia de alimentos, produtos florestais, silvicultura tropical, agronomia, entomologia e clima e recursos hídricos), além de um núcleo de pesquisas em ciências sociais. Além da área da pesquisa, o Inpa atua também na formação de recursos humanos através do seu Programa de Pós-Graduação em Biologia Tropical e Recursos Naturais, possuindo atualmente nove cursos de pós-graduação, sendo cinco de mestrado e quatro de doutorado (biologia de água doce e pesca interior; botânica; ecologia; entomologia - mestrado e doutorado; ciências de florestas tropicais, só mestrado). Esses cursos já formaram, de 1975 a 2002, 680 alunos, sendo 552 de mestrado e 128 de doutorado. Em 2002 estavam matriculados 189 estudantes, sendo 117 de mestrado e 72 de doutorado, muitos dos quais eram estudantes originários de países da Pan-Amazônia (www.Inpa.gov.br/ pos-graduação, 2003).

A principal fonte de recursos do Inpa provém do orçamento do governo federal (salários) e de recursos alocados no Plano Pluri-Anual (PP.A) aprovado pelo Congresso. Em 2001 as ações previstas no PP.A somaram R\$ 10,84 milhões, sendo que pouco mais de $60 \%$ desse valor destinou-se à manutenção dos serviços da administração. Os recursos extra-PP.A em 2001 somaram RS\$ 9,275 milhões, sendo parte deles resultante de projetos de cooperação internacional. As principais fontes extra-orçamentárias foram: Bird/ PADCT/ MCT; contrapartida do MCT ao projeto de cooperação com a Agência de Desenvolvimento do Japão (JICA); Capes/MEC, Fundação Nacional de Saúde (FNS/MS); Suframa; Finep/MCT; Programa Piloto para a Proteção das Florestas Tropicais do Brasil (PP.G-7); Fundo do Petróleo; CNPq; Banco de Desenvolvimento da Amazônia (Basa); Cooperação Internacional (onze projetos); Large Scale Biosphere Atmosfere Experiment In Amazonian (LBA/Nasa).

Quanto a publicações, os 190 pesquisadores do Inpa em atividade em 2001 apresentaram 563 trabalhos em eventos (485 resumos e 78 trabalhos completos); publicaram 232 artigos ( $146 \mathrm{em}$ revistas nacionais e $86 \mathrm{em}$ internacionais); produziram 66 livros e capítulos (37 nacional e 29 internacional). A média de publicações em 2001 foi de 1,22 artigos por pesquisador/ano, um pouco acima da média nacional estimada pelo $\mathrm{CNPq}(1,1)$.

Desde 2001, o Inpa vem trabalhando com o MCT através da assinatura de Termos de Compromisso de Gestão, que definem os objetivos e avaliam os resultados do instituto em termos do grau de atingimento das metas. O MCT introduziu uma série de parâmetros a serem avaliados, entre os quais se incluem o Índice de Publicações Vinculadas a Convênios Internacionais (IPVCI) e o Índice de Incremento Médio das Coleções Científicas, que dizem respeito especificamente aos programas de cooperação internacional. 
A área de cooperação internacional está atualmente subordinada à Assessoria de Relação Institucionais (Arin), que ainda está longe de ter um sistema de informação confiável, eficaz e atualizado que permita acompanhar a execução dos vários programas e projetos. Conforme registros oficiais, o Inpa possui atualmente nove convênios com instituições estrangeiras e internacionais ${ }^{3}$. Vários destes convênios existem há décadas mas, o Inpa ressalta em seu site que,

atualmente, só estão sendo firmados e renovados os antigos convênios entre o Inpa e o Jica, Orstom, Dfid, Cirad, Max-Planck, OMS, SUL-SUL, Universidade de Washington e Smithsonian Institution desde que o contrato de convênio permita a atuação de pesquisadores brasileiros em seus projetos propostos na região amazônica e emitam anualmente um relatório a respeito do andamento do projeto, descobertas, atividade que cada pesquisador desempenhou durante o decorrer do ano etc.

No dia $1^{\circ} / 4 / 2003$, a coordenação do projeto LBA (Large Scale Biosphere Atmosfere Experiment In Amazonian - Experimento de Grande Escala da BiosferaAtmosfera da Amazônia - MCT/ Nasa/ União Européia) teve sua administração transferida do Instituto Nacional de Pesquisas Espaciais (Inpe) para o Inpa. São exatamente esses convênios aqui listados a base sobre a qual se construíram as visões sobre a cooperação internacional que serão apresentadas e discutidas na próxima seção.

\section{Visões sobre a Cooperação Internacional no Inpa}

Ainda que o Inpa tenha sido criado há mais de cinqüenta anos, e que alguns convênios de cooperação internacional sejam quase tão antigos, foi somente na última década que começaram a vir a público diversos estudos, análises e opiniões fundamentadas abordando distintos aspectos que, direta ou indiretamente, tratam da cooperação científica internacional naquele instituto. Tais visões são apresentadas na forma de dissertações, teses, artigos, monografias, pesquisas de opinião, avaliações, estudos, relatórios de comissões criadas pelo MCT e planos institucionais ${ }^{4}$.

Em 1993, pouco antes de se tornarem públicos alguns desses trabalhos, dirigentes, pesquisadores e autoridades convidadas ${ }^{5}$ reuniram-se durante três dias para avaliar os convênios de cooperação internacional do Inpa. A opinião predominante entre os participantes, que analisaram uma série de documentos e dados, era que essa cooperação científica internacional - então expressa em 24 convênios em execução e vinte em negociação - dava-se de forma subordinada, atendendo mais aos interesses dos participantes estrangeiros; não obedecia a uma diretriz institucional, com pouco ou nenhum controle, acompanhamento e avaliação dos convênios; ocorria sem participação ativa de pesquisadores brasileiros e com pouca ou nenhuma internalização dos resultados. As negociações desses convênios davam-se, muitas vezes, à revelia do Inpa, sendo realizada em Brasília, por pessoas que não representavam nem os interesses do Inpa, nem os da região (Val \& Higuchi, 1994). Mas, apesar desse diagnóstico negativo, os participantes 
reconheciam unanimemente a importância da cooperação estrangeira na institucionalização do Inpa.

Segundo José Seixas Lourenço (ASPI-ACI/Inpa, 1993), que na época da avaliação referida acima era diretor do Inpa, o órgão, desde a sua criação, foi alvo de intensa atividade de cooperação internacional, motivada pelo interesse da exploração científica da riqueza genética, de espécies e de ecossistemas da Amazônia. Só que, com o correr do tempo, disse Lourenço (1994), a fragilidade institucional do Inpa acabou gerando uma incômoda dependência do Instituto com relação aos projetos internacionais, com os coordenadores estrangeiros assumindo, muitas vezes, uma postura mais de "chefes", “bosses" ou "kaisers" do que de verdadeiros parceiros. Como decorrência, a própria sociedade amazonense, incluindo o governo do Estado $^{6}$, costumava ver o Inpa como uma base científica para pesquisadores estrangeiros, com pouco retorno para a comunidade regional.

Logo depois desse fórum, Lourenço estabeleceu uma portaria (datada de 24/6/1993) regulamentando a execução de projetos realizados por meio de convênios estrangeiros e internacionais no Inpa. Pela leitura dessa portaria depreende-se que, até então, esses projetos não eram necessariamente submetidos à aprovação da direção do Inpa. Também através dessa portaria ficou estabelecido que cada projeto deveria obrigatoriamente alocar recursos necessários ao ressarcimento dos custos indiretos do Inpa (overhead), mas isso nunca chegou a ser implementado.

Outra iniciativa da administração de Seixas Lourenço no ano seguinte foi a criação de um Grupo de Trabalho sobre Cooperação Interinstitucional do Inpa. Esse grupo de trabalho, ao final de uma série de reuniões, constatou que "os interesses dos parceiros estrangeiros na cooperação internacional oferecida muitas vezes não atendem as prioridades da instituição" e que "não há um acompanhamento efetivo das ações de cooperação internacional no que tange aos principais pontos acordados entre as partes envolvidas, suas obrigações e direitos". (GT/ Inpa, 1994, p. 3).

Ainda em 1994, o Ministério da Ciência e Tecnologia (MCT) designou uma comissão (que ficou conhecida como Comissão Bevilácqua) com o fito de avaliar os institutos então ligados ao CNPq e aqueles ligados ao próprio MCT. O relatório final apresentado destacou a importância da cooperação internacional para o desenvolvimento científico e tecnológico nacional e recomedou que, nesse contexto, o Inpa deveria aprimorar e intensificar o intercâmbio com instituições de ensino e pesquisa nacionais e estrangeiras. No entanto, depois de frisar que o Inpa tem servido de laboratório internacional para várias instituições estrangeiras [são citados especificamente os Institutos Max Planck (Alemanha), Orstom (França), ODA (Inglaterra) e Smithsonian (EUA)] o relatório conclui que

O entrosamento entre as equipes do Inpa e suas equivalentes estrangeiras tem deixado muito a desejar, trazendo como conseqüência uma falta de comuni- 
cação entre os cientistas brasileiros e estrangeiros. Estes freqüentemente trabalham isolados, não divulgando aqui os resultados de suas investigações (Comissão Bevilácqua, MCT, 1994, p. 33) ${ }^{7}$.

Nessa mesma linha foi a análise do pesquisador do Inpa, Peter Weigel (1994, p. 533) que, em sua dissertação de mestrado diz que:

A cooperação estrangeira, presente na vida do Instituto, em maior ou menor grau, desde a sua implantação, sempre despertou controvérsias em nível interno. Esta questão, apesar das regulamentações existentes, tendeu sempre a ser tratada com excessiva flexibilidade, gerando uma situação muito vantajosa para grupos de pesquisas estrangeiros.

Em um país como o Brasil, que não consegue formular diretrizes claras de ciência e tecnologia e em um instituto de pesquisas, como o Inpa, que não consegue articular claramente seus objetivos e diretrizes de pesquisa, qualquer pesquisa a respeito da Amazônia tende a ser considerada importante e aceitável, exceto aquelas que representam claras duplicações de atividades já em realização no País. Nesse sentido, as diretrizes que orientam a aprovação ou não de projetos tendem a ser muito flexíveis, apoiando-se mais no mérito científico dos projetos, do que no significado político e econômico desses projetos em si. Essa situação faz com que grupos estrangeiros tenham facilidade em aprovar programações completas de pesquisas, passando a atuar de forma autônoma. Nesse esquema, a cooperação estrangeira não representa mais o auxílio científico e tecnológico em lacunas muito bem definidas em projetos nacionais, mas passa a ser auxílio brasileiro para adequado desenvolvimento das programações estrangeiras, em uma inversão de valores e expectativas pouco interessante para o país, porém coerente com a situação de dependência científica, tecnológica e econômica em que se encontra o país.

Weigel (1994, p. 535 ) procurou saber a opinião dos pesquisadores do Inpa a respeito da cooperação internacional do órgão. Entre as conclusões, ressalta que:

a crise econômica brasileira e as restrições orçamentárias do Inpa, transformou os grupos estrangeiros em atividade no Inpa em incômodas ilhas de prosperidade e desempenho. Nesse sentido, esses grupos, ancorados em sólidos e abrangentes convênios, aumentaram muito seu peso político no instituto e seu poder de barganha, na medida em que suas atividades não sofrem problemas de continuidade por falta de recursos. As percepções expostas nos questionários mostram que a intensificação da cooperação estrangeira aparece como uma opção viável para alocação de recursos diversos, principalmente financeiros. Assim, em face da crescente ausência estatal, o aumento da presença estrangeira aparece como única opção para continuidade das atividades de pesquisa. Essa situação não é isenta de riscos, na medida em que, na ausência de prioridades institucionais, as prioridades estrangeiras, antes disfarçadas em disposições paradigmáticas diversas, tendem a tornar-se prioridades institucionais.

Weigel (1994) argumenta ainda que é possível agrupar os pesquisadores do Inpa em três categorias, de acordo com o tipo de percepção que eles têm sobre a cooperação estrangeira. O primeiro grupo considera que a cooperação internacional tem um papel importante, principalmente por trazer recursos sem 
problemas de continuidade, formar pessoal, possibilitar treinamento no exterior, fornecer equipamentos e materiais, permitir o acesso a publicações estrangeiras e realizar uma rápida divulgação dos resultados. A segunda percepção considera essa cooperação importante, mas julga necessário que ela seja melhor controlada e que atenda prioritariamente aos interesses nacionais. A terceira percepção é a de que a cooperação estrangeira é importante apenas como complemento a carências específicas do Inpa e deve estar sob rígido controle nacional ou institucional.

Na pesquisa de Weigel ficou claro que a atual cooperação estrangeira apresenta sérios inconvenientes, tais como: cooptação, utilização subalterna de pessoal local, coleta e retirada de material do país sem nenhum controle, pouco acesso aos conhecimentos gerados, crescente ingerência nos assuntos internos do Inpa e formação de instâncias de difícil controle administrativo e científico. Em suma, nos moldes em que vem se desenvolvendo, apesar de ser considerada importante, foi encarada com desconfiança e se recomendou sua reformulação.

Estudos da cooperação internacional do Inpa realizadas por pesquisadores externos à instituição chegaram a conclusões semelhantes. Um desses estudos, a partir de documentos e entrevistas, concentrou a análise nos seguintes aspectos: processos de negociação e gerenciamento; divisão das tarefas entre as partes; divisão e origem dos recursos; esforço intelectual conjunto; publicações (Velho, 1994). As principais conclusões da autora foram:

- O Inpa foi escolhido como instituição contraparte brasileira não pela capacitação científica que possui em pesquisa biológica na Amazônia, mas pelo acesso que ele propicia ao maior e mais importante laboratório natural do planeta. Assim, diferentemente do que ocorre na cooperação envolvendo países avançados, em que as parcerias se estabelecem porque cada lado tem interesse no que o outro pode fornecer em termos de conhecimento e capacitação, a cooperação entre norte-sul se dá principalmente pelo interesse que têm os países no norte em explorar cientificamente ambientes que só estão disponíveis no países do sul;

- a participação dos pesquisadores brasileiros nos processos de negociação e gerenciamento dos projetos foi muito reduzida. Eles aparecem como o "lado fraco" e, quando são apresentados aos projetos, devem decidir apenas se participam ou não a partir de propostas previamente fechadas. A iniciativa das colaborações invariavelmente é dos estrangeiros;

- o Brasil deixa sistematicamente de cumprir sua parte no financiamento dos projetos de cooperação aprovados. Assim, dada a penúria financeira em que se encontra o Inpa (1994), ele tem ficado a reboque de projetos internacionais mal discutidos pois, aquele que detém os recursos acaba tomando as principais decisões. "A cooperação internacional tem sido usada no Inpa como 'expediente' para resolver problemas de caixa ou contratar pessoal. Nessas condições, os recursos acabam indo para projetos de interesse dos financiadores estrangeiros e não para aqueles julgados importantes pelo país receptor" (p. 24); 
- a cooperação internacional (do Inpa) é essencialmente assimétrica quanto aos recursos humanos envolvidos nos projetos, sendo muito maior a capacitação dos estrangeiros que, aliás, valorizam muito mais a contribuição dada pelos técnicos e auxiliares de campo brasileiros do que a dos pesquisadores;

- os projetos de cooperação (do Inpa) não têm resultado numa produção científica co-autorada significativa e os cientistas estrangeiros geralmente aparecem como autores principais.

Na mesma linha de análise, Toni (1994) elaborou uma dissertação de mestrado sobre a cooperação científica entre o Brasil e a França tendo como foco principal os convênios de cooperação entre Inpa/CNPq/Orstom e Inpa/CNPq/ Cirad. Toni concluiu que há uma grande fragilidade institucional por parte do Inpa e também do CNPq (responsável formal pelos convênios) e nessa situação os convênios sequer eram avaliados. Toni constatou que, durante longo tempo, os pesquisadores franceses trabalhavam sozinhos em temas e tópicos que sequer eram pesquisados pelo Inpa, o que demonstra que a cooperação científica estava mais voltada à resposta de questões científicas de interesse primordial da França. Constatou também um grande desequilíbrio na produção científica, francamente favorável aos pesquisadores franceses.

Diagnóstico semelhante foi feito, também, desta vez por uma pesquisador do próprio Inpa (Guimarães 1994, p. 24). Segundo este pesquisador:

Dentre os principais riscos existentes na cooperação internacional, pode-se citar como o primeiro deles a possibilidade de o Inpa se tornar uma mera base física de pesquisa, com toda sua experiência e apoio logístico e de pessoal, para atender aos interesses dos grupos externos. Outro grande risco que corre o Inpa é o de facilitar a entrada de grupos estrangeiros que visam simplesmente à coleta de dados e material científico na região para o desenvolvimento de projetos isolados, que podem incluir até interesses econômicos, sem a participação do lado brasileiro. Em vista disso, o Inpa deve estar sempre alerta para os projetos que podem comprometer o uso e a salvaguarda da biodiversidade amazônica. O estabelecimento de normas rígidas de controle das atividades estrangeiras na região torna-se necessário, a fim de se prevenir contra esses problemas.

Entretanto, apesar desses diagnósticos, foi consenso de que havia, no início da década de 1990, uma conjuntura política favorável à cooperação e disposição de outros países para celebração de acordos de cooperação, bem como interesse de vários organismos internacionais em cooperar, tecnicamente, na solução dos grandes problemas da Amazônia (Sudam/ PNUD/ GTZ, 1992).

Assim, numa reunião realizada em Houston (EUA) antes da Conferência Mundial sobre Meio Ambiente e Desenvolvimento (Rio-92), os países integrantes do chamado Grupo dos 7 - G-7 - (os sete países mais ricos do Mundo) anunciaram a intenção de criar um fundo de US\$ 1,5 bilhão destinado à salvação das florestas tropicais (Marcovitch, 1994). 
Apesar de essa intenção ter ficado no papel durante cinco anos, finalmente foram liberados recursos destinados a um programa de conservação das florestas tropicais brasileiras administrado pelo Banco Mundial e financiado com recursos do G-7. Dentro desse programa, foi criado um componente de fortalecimento institucional dos institutos de pesquisa da Amazônia, especialmente Inpa e o Museu Paraense Emílio Goeldi, num projeto chamado Centros de Excelência. De fato, no Inpa, foram construídos novos prédios e melhorada a rede de eletricidade, telefone, água e rede de computadores.

Como uma das etapas para a transformação do Inpa em centro de excelência, foi elaborado, em 1993, um programa de planejamento estratégico, que considerou que o volume de convênios internacionais em execução, assim como a grande facilidade de firmar novos acordos internacionais, era um ponto forte do instituto, que devia ser explorado.

Durante a elaboração do programa de planejamento estratégico foram desenhados vários cenários para o Inpa até o ano de 2002. Um desses cenários foi o de desenvolvimento sustentável que previa, no plano internacional, que as correntes de conservação do ecossistema amazônico apoiariam o aumento de recursos para o financiamento de C\&T e o mercado internacional aumentaria sua demanda de produtos regionais oriundos do manejo sustentável. A cooperação teria importância crescente e as atenções mundiais sobre a Amazônia destacariam a importância estratégica da biodiversidade.

Nessa linha de análise, José Galízia Tundisi (1993), então presidente do CNPq, ao fazer a "Análise da auto-avaliação do Inpa", chamava a atenção para o fato de que era preciso haver:

O melhor e mais efetivo aproveitamento da participação de pesquisadores de outros países na pesquisa e formação de recursos humanos da Instituição.

Em muitos casos, há um isolamento grande de pesquisadores de alto nível, os quais poderiam contribuir mais efetivamente para o treinamento de recursos humanos e a pesquisa na Instituição. Esse isolamento, em parte decorre da urgência de um plano estratégico de longo prazo, o qual poderia engajar estes pesquisadores em projetos do Inpa e não de interesse externo. É preciso colocar aqui a pergunta: até que ponto a pesquisa científica do Inpa, que sem dúvida tem gerado inúmeros dividendos e reconhecimento, foi endógena e as questões resolvidas ou as perguntas que surgiram foram resultado de um processo interno de desenvolvimento científico? Ou vieram a reboque de idéias (sem dúvida excelentes) geradas por pesquisadores de fora do país? Até que ponto, idéias expressas em trabalhos, hipóteses etc. foram internalizadas no Inpa e utilizadas conceitualmente pelos pesquisadores do Inpa na resolução dos inúmeros e prementes problemas amazônicos e na formação de recursos humanos?

Não há dúvida que a contribuição de inúmeros cientistas do exterior ao Inpa e à pesquisa amazônica foi notável, incluindo-se aí a formação de recursos humanos. Deve-se entretanto insistir na questão: há um processo endógeno (digo local, genuíno) de interesse intelectual, na Amazônia de toda a classe de 
pesquisadores do Inpa? Este problema deve ser repensado, analisado e bem desenvolvido na elaboração do plano estratégico de longo prazo (Tundisi, 1993, p. 8).

Tundisi fez, entre outras, a seguinte recomendação:

Reavaliar e reconduzir a cooperação internacional cuja contribuição nunca foi realmente analisada em detalhe. É preciso incorporá-la aos projetos prioritários do Inpa, buscar meios e mecanismos para internalizá-la e torná-la mais efetiva para o Inpa (Tundisi, 1993, p. 9).

Também trabalhando de uma perspectiva mais interna ao Inpa, Gama (1997) analisou um projeto norte-americano denominado Projeto Dinámica Biológica de Fragmentos Florestais (inicialmente denominado Projeto Tamanho Minimo Crítico de Ecossistemas) que foi levado a cabo por instituições daquele país em Manaus (AM), inicialmente sob o patrocínio do WWF/US e posteriormente do Smithsonian Institution. Durante o período WWF/US (1979-1991) o projeto era tratado como uma expedição científica e, a partir de 1991, virou um convênio de cooperação entre o Smithsonian e o Inpa. O trabalho de Gama (1997) analisou três parâmetros: participação brasileira (inclusive formação de recursos humanos) vis-à-vis a estrangeira; publicações (quantidade e primeiros autores) e destino do material científico coletado. O trabalho mostrou que em todos os itens analisados o Inpa havia sido um beneficiário menor do programa.

Ainda em 1997 foi publicado o Relatório Final da Comissão do Congresso Nacional, criada para apurar denúncias de exploração e comercialização ilegal de plantas e material genético da Amazônia (Congresso Nacional, 1997). Essa Comissão tratou também dos aspectos institucionais da cooperação científica internacional e recebeu da direção do Inpa um quadro que indicava que era comum um único pesquisador brasileiro ser o responsável nacional pela cooperação com três ou mais instituições de pesquisa estrangeiras. Com base nesta e outras informaçcões, a comissão recomendou, com destaque, que o Poder Executivo tomasse medidas urgentes para garantir o acompanhamento dos convênios de cooperação internacional, exigindo avaliações anuais dos projetos e programas e uma participação mais efetiva da contrapartida brasileira. Também recomendou medidas para o fortalecimento das assessorias de cooperação internacional das instituições de ensino e pesquisa da região amazônica.

Em 1998, a Associação dos Pesquisadores do Inpa (Aspi) tomou a inciativa de elaborar uma pesquisa de opinião com 118 pesquisadores do órgão. Mais uma vez, os resultados obtidos anteriormente foram confirmados. A maioria dos pesquisadores considerou que esses convênios só executam o que interessa à parte estrangeira que, conseqüentemente, é a maior beneficiária; faltam programas brasileiros bem definidos para que o Inpa possa negociar suas prioridades; não há contrapartida equivalente do Inpa em termos de recursos humanos e financeiros disponibilizados pelos estrangeiros; o Inpa entra com sua infra-estrutura e apoio logístico e recebe quase nada em troca. Os pesquisadores consideram ainda que 
esses convênios são muito seletivos e oferecem melhores condições de trabalho e equipamentos para um grupo restrito de colegas, para os quais não faltam verbas, que são mais fáceis de usar, pois não passam pela burocracia governamental. O principal benefício apontado é o intercâmbio com cientistas estrangeiros de alto nível, o que contribui para a reputação da instituição e lhe dá reconhecimento internacional (Jornal da Aspi, 84, 10/6/1998). Foi proposta a revisão de todos os convênios, depois de uma avaliação a fim de aumentar os benefícios para a parte brasileira, bem como um maior controle da entrada e saída de pesquisadores estrangeiros.

A maioria dos pesquisadores considerou ainda que o acompanhamento dos convênios é precário, sendo o controle institucional meramente burocrático. Conseqüentemente, os acordos são, na prática, apenas a formalização legal da instituição estrangeira no Brasil. Foi lembrada também a questão ética, apontando a existência de pesquisadores que formalizam uma contrapartida inexistente, bem como aqueles que "vestem a camisa" do país do convênio e emprestam seu nome para legitimar as excursões estrangeiras em troca de visitas ao exterior e passagens para congressos internacionais ${ }^{8}$.

Com relação ao controle que o Inpa exerce sobre a saída de material biológico coletado através de convênios internacionais, a expressiva maioria dos pesquisadores do Inpa ouvidos na pesquisa da Aspi mostrou que o Inpa não exerce controle algum, pois não existem regras efetivas, nem fiscalização e a legislação não assegura um controle real. Brasileiros e estrangeiros desconhecem a legislação e há inúmeros casos de saída de material sem registro. Os pesquisadores estrangeiros vão e vêm e não há controle algum da saída de material, que fica ao bel-prazer dos participantes, existindo até mesmo casos de biopirataria (Jornal da Aspi, 84, 10/6/1998, p. 3).

No mesmo sentido foi o relatório de inteligência no $0026 / 4310 /$ DCI/ ABIN/20/4/2001 (doc. 13) que apontou deficiências no controle da atividade de pesquisadores estrangeiros na Amazônia e citou o Inpa com destaque. De acordo com tal relatório, os instrumentos jurídicos nacionais e a estrutura especializada do Estado voltada para a regulamentação e controle das atividades de estrangeiros no País não têm impedido a saída ilegal de material nacional e que pesquisadores brasileiros têm contribuído de maneira decisiva para a realização de pesquisa ilegal e a coleta de material não autorizado por cientistas vinculados a instituições estrangeiras. Esse relatório foi longamente analisado por técnicos do MCT, que apontaram efetivos problemas na redação e implementação do dec. $\mathrm{n}^{\mathrm{o}}$ 98.830/90 e Portaria MCT no $55 / 90$.

Seguindo a cronologia, em 2001-2002 o MCT criou uma Comissão destinada a avaliar as 22 unidades de pesquisa do MCT. Essa comissão ficou conhecida como "Comissão Tundisi" e contou com a colaboração de 72 cientistas nacionais e estrangeiros. Foram elaborados dois relatórios, sendo um genérico e outro específico para cada unidade de pesquisa do MCT. Com relação ao primeiro, a 
Comissão entendeu, em resumo, que as seguintes ações são fundamentais para integração do desenvolvimento sustentável da Amazônia ao desenvolvimento nacional: consolidação e reforço dos programas dos institutos (Inpa, Goeldi e Mamirauá), e mobilização da comunidade científica nacional e internacional para aprofundar os estudos em andamento nessas e outras instituições da área e diversificar e aprofundar a formação de recursos humanos para a região; reformulação das estratégias de participação da comunidade científica internacional no desenvolvimento de projetos de interesse do Brasil e suas instituições, de forma permanentemente compartilhada (p. 26).

A avaliação do Inpa foi feita por um comitê externo formado pelos pesquisadores Evaristo Eduardo de Miranda (Embrapa), Francisco de Assis Esteves (UFRJ), Mahabir P. Gupta (Cyted) e Roberto Brandão Cavalcante (UnB), que visitou o Inpa durante três dias. $\mathrm{O}$ relatório final apresentado por esse comitê reconhece a liderança do Inpa na Amazônia no que diz respeito a pesquisas relacionadas à ecologia e à conservação da biodiversidade devido à existência de cientistas bem qualificados, bons programas de pós-graduação e projetos de cooperação nacional e internacional altamente relevantes.

No que diz respeito especificamente à cooperação internacional do Inpa, o relatório recomenda a "implantação, a curto prazo, de mecanismos de avaliação (externos e independentes) dos programas de cooperação internacionais" (p. 7) [negrito do original]. Segundo ainda esse relatório, o forte envolvimento do Inpa com a cooperação internacional deverá continuar, mas reconhece que a seleção dos seus projetos de cooperação do Inpa têm sido dirigidos pela oferta internacional e não pela demanda nacional que também deve ser atendida.

Outra recomendação do relatório é a de que sejam estabelecidos os mecanismos de gestão e operacionalização dos programas de cooperação internacional que deveriam estar baseados num manual de procedimentos e de conduta claramente estabelecido (interesses nacionais, paridade científica, manuseio de recursos financeiros, formação de recursos humanos, contrapartida nacional, soberania científica, indicadores de avaliação e acompanhamento etc.) (p. 7).

O relatório coloca também como prioridade que o Inpa se torne uma coordenação regional da realização de novas expedições de coleta, a fim de fortalecer suas coleções científicas.

Nos dias 20 e $21 / 11 / 2002$, os dirigentes das unidades de pesquisa do MCT reuniram-se em Brasília para discutir, entre outros assuntos, os procedimentos para a cooperação internacional (Gestão C\& T Eletrônico, 20/12/2001). Como resultado desse workshop, o MCT editou a Portaria no 814, de 16/12/ 2002, aprovando o Manual de Procedimentos para Atividades de Cooperação Internacional na Área de CêT, elaborado por integrantes da Secretaria de Coordenação das Unidades de Pesquisa do MCT, da Consultoria Jurídica, da Assessoria de Cooperação Internacional (MCT), e do Conselho Nacional de Desenvolvimento Científico e Tecnológico-CNPq, para utilização por todas as unidades internas e externas deste Ministério. 
Finalmente, em agosto de 2004, a convite da diretoria do Inpa, reuniu-se uma comissão externa para avaliar os programa de cooperação internacional do Inpa ${ }^{10}$ de uma forma geral e tratar especificamente dos convênios Inpa/ Smithsonian Institution (EUA) e Inpa/ Max-Planck Institut für Limnology (Alemanha). A comissão reconheceu que a cooperação internacional do Inpa, nos últimos dez anos, tem sido objeto de acaloradas discussões e debates e vários diagnósticos têm sido realizados apontando pontos positivos e negativos dessa cooperação, mas que os problemas persistem e que quase nada tem sido feito para implementar as recomendações feitas nos anos anteriores. Assim, essa comissão sugeriu, entre outras coisas: que o Inpa defina sua política de cooperação internacional a partir de debates com os atores internos e externos; que o Inpa defina, para cada projeto, os objetivos específicos, as metas a serem alcançadas e os instrumentos a serem usados; e que seja composto um comitê de assessoramento independente que possa orientar, convalidar e avaliar esse projetos, já que nem os relatórios são avaliados.

Coroando as análises anteiores, Gama (2004) analisou estatisticamente os convênios do Inpa pós-edição do Dec. 98.830/90 e Portaria MCT 055/90 em sua tese de doutorado recentemente defendida. Constatou que, no Inpa, a modalidade de pesquisa científica estrangeira realizada por meio de expedições científicas controladas pelo $\mathrm{CNPq}$ deixou de ter relevância, representando, durante a década de 1990, apenas 2,54\% dos pesquisadores estrangeiros recebidos por pesquisadores do Inpa. A nova modalidade de "cooperação" passou a se basear em uma política de simples emissão de cartas convites a pesquisadores estrangeiros sem que haja qualquer avaliação prévia, rigorosa e representantiva por parte do intituto. Dessa forma, o controle sobre a pesquisa científica estrangeira tem deixado muito a desejar e agravou-se ainda mais com a transferência da coordenação do Projeto LBA do Inpe (CPTEC) para o Inpa. A quantidade de pesquisadores e entidades estrangeiras envolvidas é espetacular e certamente ainda precisa ser feito um levantamento das perdas e ganhos desse convênio.

Em síntese, todos os diagnósticos aqui apresentados mostram que a cooperação internacional do Inpa precisa ser reestruturada a fim de melhor servir aos interesses nacionais e ao desenvolvimento sustentável regional.

\section{Conclusões}

A própria criação do Inpa, em 1952, demonstra, entre outras coisas, que a iniciativa da pesquisa científica na Amazônia vinha de fora para dentro. De fato, o Inpa foi criado em contraposição a um outro instituto, de caráter internacional, proposto e acalentado no sistema ONU (Unesco). Com a criação do Inpa, o Brasil passou a dispor de uma certa iniciativa na pesquisa e se tornou, pelo menos formalmente, contrapartida à demanda estrangeira.

Com a criação do Inpa vinculado ao também recém-criado Conselho Nacional de Pesquisas - CNPq, o instituto passou a se subordinar à política de cooperação científica internacional elaborada por este. Essa política tinha por 
princípio transformar todos os projetos de pesquisa estrangeiros que não fossem de interesse imediato do Brasil em "expedição científica" e controlar a saída do material científico coletado. Essa prática vinha desde 1933, quando foi criado o Conselho de Fiscalização das Expedições Científicas e Artísticas Estrangeiras no Brasil. Desse modo, o CNPq passou a utilizar o Inpa como contrapartida nacional das expedições científicas de iniciativa estrangeira na Amazônia Ocidental ${ }^{11}$. Entre os exemplos de projetos estrangeiros que foram transformados em expedição científica pode-se citar os projetos Flora Amazônica e o PDBFF/WWW-US. Também fazia parte dessa política reativa, a iniciativa do CNPq de tentar nacionalizar os projetos estrangeiros, colocando-os sob a liderança de pesquisadores nacionais e/ou criando programas alternativos sob a liderança de nacionais.

É importante reconhecer que o CNPq procurou manter algum controle formal sobre as expedições científicas estrangeiras, num processo que evoluiu a ponto de ser uma das exigências a avaliação prévia por consultores ad hoc. A partir de 1987, o Inpa passou a se subordinar administrativamente ao MCT. Por conseguinte, a cooperação científica internacional, até então sob controle do CNPq, ganhou maior autonomia e o Instituto passou a assinar seus próprios convênios.

Os dados apresentados por Gama (2004), contrastando a entrada de pesquisadores estrangeiros no Inpa por meio de expedições científicas na década de 1990 com aqueles que ingressaram através de cartas-convite emitidas pelo Inpa, no mesmo período, evidenciaram que houve uma substancial alteração na forma de ingresso de pesquisadores estrangeiros para atuar em projetos na Amazônia, tendo o Inpa como co-responsável, muito em função da nova legislação (decreto 98.830). Os dados mostraram também que os principais beneficiários deste novo formato foram, principalmente, dois grandes projetos de iniciativa de instituições estrangeiras: o Projeto Dinâmica Biológica de Fragmentos Florestais - PDBFF (convênio com a Smithsonian Institution dos EUA) e o projeto ecologia de áreas alagáveis na Amazônia (convênio com o Max-Planck - Institute für Limnologie da Alemanha), que envolvem uma grande quantidade de pesquisadores estrangeiros em contraste com o reduzido nœmero de pesquisadores do próprio Inpa. Mostrou também o elevado grau de autonomia que os coordenadores estrangeiros desses convênios adquiriram ao longo do tempo com relação ao ingresso de participantes forâneos, sem que o Inpa tenha institucionalizado qualquer tipo de avaliação prévia ou a posteriori, desempenhando papel como mero coadjuvante.

Em vista do exposto acima, pode-se concluir que existe uma enorme convergência na visão dos mais variados analistas da cooperação internacional no Inpa. Sejam pesquisadores externos ao Inpa, sejam os próprios pesquisadores do instituto, sejam representantes de organismos governamentais ou de organizações não governamentais, a opinião corrente é que as coisas não podem continuar como estão. Mais do que uma concordância quanto ao diagnóstico, as idéias convergem também quando aos fatores explicativos e às medidas que devem ser 
tomadas para solucionar os problemas identificados. O que falta, agora, é ação. As razões que levam ao imobilismo depois de mais de dez anos de repetição do diagnóstico é que talvez tivessem, nesse momento, que ser investigadas. Enquanto nada se faz, tudo continua como sempre foi...

\section{Notas}

1 Tais exigências incluíam: análise prévia do projeto por instituições de pesquisas nacionais ligadas ao objeto da pesquisa a ser realizada; nomeação de uma instituição nacional co-participante e co-responsável; designação, pelo MCT, de um pesquisador para servir de contrapartida nacional, entre muitas outras. Pela nova regulamentação, as instituições estrangeiras interessadas em fazer pesquisa no Brasil foram estimuladas a estabelecer "convênios de cooperação internacional" com instituições nacionais, passando, dessa forma, a obedecer à sistemática estabelecida nos convênios que, por sua vez, podem ser redigidos de forma tão flexíveis a ponto de dar margem à unilateralidade na política de pesquisas por parte dos parceiros estrangeiros.

2 Quando o Inpa foi criado, existiam apenas duas universidades federais na região Amazônica brasileira. Hoje existem universidades federais em todos os oito estados da região, três estaduais e cinco institutos de pesquisas federais, além de dezenas de universidades privadas. Apenas duas instituições promovem cursos de pós-graduação em nível de doutorado (Inpa e UFPA). Segundo o Relatório Tundisi (2001), o problema da fixação de recursos humanos de alto nível na Amazônia persiste, pois a região possui apenas oitocentos doutores, metade dos quais envolvidos com funções administrativas. Para se ter uma idéia, o Brasil forma atualmente seis mil doutores por ano.

3 No entanto, o site do Inpa informa que, em 2003, somente a Coordenação de Pesquisas em Ecologia do Instituto contava com o apoio de onze projetos e convênios internacionais: 1) Projeto: Jacaranda - Convênio MCT/Inpa/ Jica - (Japão); 2) Projeto: Implantação de Metodologias de Análises Especiais em Solos e Vegetação - Convênio: MCT/Inpa/ABC/IRD (França); 3) Projeto: Dinâmica Biológica de Fragmentos Florestais (PDBFF) - Convênio: MCT/Inpa/Smithsonian Institution; 4) Projeto: Fauna do solo e decomposição de liteira em floresta primária e secundária e numa área de policultivo na Amazônia - Programa SHIFT de Cooperação Teuto-Brasileira CNPq/ Ibama/ DLR; 5) Projeto: Biogeoquímica do Carbono no Rio Amazonas Convênio CNPq/ NSF/ Inpa/ Cena/ Universidade de Washington; 6) Projeto: Eosram - Earth Observing System Regional Amazon Model - Convênio: MCT/ Inpe/ Inpa/ Cena/ Universidade de Washington/ Universidade da California/ Goodard Space Flight Center; 7) Projeto LBA - Large Biosphere-Atmosphere Project on Interaction in the Amazon Basin. - Convênio: Nasa/ MCT/ Inpe/ MCT/ Inpa/ Embrapa/ Cena-SP/ USP / UnB; 8) Projeto: Mudanças antropogênicas no uso de terra e dinâmica de biomassa e na floresta amazônica - PDBFF/ Smithsonian/LBA/ Nasa; 9) Projeto de Pesquisa Dirigida (PP.D): As interações entre florestas e savanas e seu efeito na biodiversidade - União Européia/ MCT/ Finep/ Inpa; 10) Convênio Inpa/ Aeci (Agencia Espanhola de Cooperação Internacional); 11) Projeto: Biodiversidade Funcional do solo e sua relação com a diversidade de plantas - MCT/ Inpa/ Ufla/ $\mathrm{UnB} / \mathrm{TGBF} / \mathrm{GEF}$.

4 Inpa/ Aspi (1993); Comissão Bevilacqua (MCT, 1994); Guimarães (1994); Toni (1994); Machado (1994); Val e Higuchi (1994); Gama (1995); Velho (1995); Toni e 
Velho (1996), Velho e Velho (1996); Gama (1997); Congresso Nacional Brasileiro (1998); Aspi - Pesquisa de Opinião (1998); Machado (1999); Comissão Tundisi (MCT, 2001), Agência Brasileira de Inteligência (Abin, Relatório de Inteligência confidencial, 2001) e Gama (2004).

5 Ministério da Ciência e Tecnologia, CNPq, Capes, Ministério das Relações Exteriores e Agência Brasileira de Cooperação do MRE.

$6 \mathrm{O}$ ex-governador do Amazonas, Amazonino Mendes, por exemplo, afirmava, em 3/ $5 / 1998$, que "em quarenta anos, qual foi o legado do Inpa para nós? Na relação custo/ benefício, verificamos que o Inpa não ofereceu praticamente nada em troca do que recebeu. No entanto, fez o nome de muitos cientistas internacionais, sobretudo alemães". (A Critica, 3/5/98)

7 A revista Ciência Hoje (vol. 18, n 107, mar. 1995, p. 60) publicou o seguinte sobre a Comissão que avaliou os institutos do MCT: "Inpa - O Inpa tem sido utilizado como base para pesquisas por vários institutos estrangeiros. Entretanto, o entrosamento com as equipes estrangeiras tem deixado muito a desejar, com pouco ou nenhum aproveitamento pelos pesquisadores do Inpa". Recomendação da Comissão n ${ }^{0} 19$ (específica para o Inpa): "Devem ser revistos os convênios de cooperação internacional, enfatizando a necessidade de benefícios para o País".

8 Machado (1999) relata, baseado em uma entrevista com um pesquisador do Inpa, o seguinte caso: "Existe no Inpa um grupo de pesquisadores formados pelos norteamericanos da universidade $\mathrm{X}$ [nome de uma cidade] que se tornou um gueto. A fim de poder lubrificar e fazer funcionar a máquina administrativa para o grupo, eles colocaram o nome de uma vice-diretora, a MNGR, em todos os trabalhos que eles publicaram. [...] Ela tem trabalhos publicados na Science e na Nature... uma lista de publicações de dar inveja porque tratava dos temas os mais variados em lugares da Amazônia onde ela nunca botou o pé e não sabe aonde fica...”. (p. 25).

9 A Comissão foi composta pelos seguintes membros: José Galízia Tundisi (Instituto Nacional de Ecologia), Carlos Alberto Schneider (Fundação Certi), Celso Pinto de Melo (CNPq), Eduardo Moacir Kieger (ABC/ Incor), Eloi S. Garcia (MCT/ Secup), Fernando Galembeck (Unicamp), José Fernando Perez (Fapesp), José Octávio Paschoal (CNEN), Ruy de Araújo Caldas (Embrapa) e Vilma Figueiredo (SBPC/ Unb).

10 Essa comissão foi formada por: Alfredo Homma, Carlos Oiti Berbert, Esper Abrão Cavalheiro, Léa Velho, Leandro Luiz Viegas e Maria Sylvia Derenusson.

11 Entre os exemplos de projetos estrangeiros que foram transformados em expedição científica podem ser citadas os projetos Flora Amazônica e o PDBFF/WWW-US.

\section{Referências}

ABIN. Relatório de Inteligência 0026/4310/DCI/ABIN/20/4/2003), 2003.

ASPI. O INPA avaliado por seus pesquisadores. Pesquisa de Opinião coordenada por GAMA, William. Caderno, 1998.

ASPI-ACI/ INPA. Fórum de cooperação internacional do INPA - Relatório dos grupos de trabalho. Manaus, Fita K-7, 1993.

BECKER, Bertha. Amazônia, hoje e sempre - www.memorialdomeioambiente. org.br/ projeto/down/bertha_becker.doc, 2003. 
BRASIL. Dec. 22.698 - Institui a fiscalização das expedições artísticas e científicas no Brasil. Diário Oficial da União, 11/3/1933.

. Dec. 23.311 - Cria o Conselho de Fiscalização das Expedições Artísticas e Científicas no Brasil. Diário Oficial da União, 31/10/1933.

Dec. 62.203 - Extingue o CFEACB e passa suas atribuições ao CNPq e à Diretoria do Patrimônio Histórico e Artístico Nacional (MEC). Diário Oficial da União, $31 / 10 / 1968$.

. Dec. 65.057 - Dispõe sobre a concessão de licença para realização de expedições científicas no Brasil. Diário Oficial da União, 26/8/1969.

. Dec. 93.180 - Dispõe sobre a concessão de licença para realização de expedições científicas no Brasil. Diário Oficial da União, 27/8/1986.

Dec. 98.830 - Dispõe sobre a coleta, por estrangeiros, de dados e materiais científicos do Brasil. Diário Oficial da União, 15/1/1990.

Congresso Nacional, Câmara dos Deputados. Relatório final da Comissão de Biopirataria na Amazônia. Câmara dos Deputados, Brasília, 1997.

Medida Provisória 2.186-16. Dispõe sobre o acesso ao patrimônio genético, a proteção e o acesso ao conhecimento tradicional associado, a repartição dos benefícios e o acesso à tecnologia e transferência de tecnologia para sua conservação e utilização. Diário Oficial da União, 23/8/2001.

CANTO, Isabel. "Uma agenda para parcerias na Amazônia". Folha de S. Paulo, Tendências/Debates, $11 / 2 / 2003$, p. 3.

GAMA, William N. G. O PDBFF (INPA/WWF-US/Smithsonian): uma base de pesquisa científica norte-americana na Amazônia Brasileira. Dissertação de Mestrado. Belém, Naea/ UFPA, 1997.

O papel do Estado na regulação do acesso de pesquisadores estrangeiros na Amazônia brasileira na década de 1990: o caso do Inpa. Tese de Doutorado, Campinas, DPCT/ Unicamp, 2004.

GT/ INPA. Workshop de Apresentação e Avaliação do Planejamento Estratégico do Inpa. Grupo de Trabalho "Estratégias para a Cooperação Inter-Institucional do Inpa". Manaus 28-29/1/1994. Conclusões.

GUIMARÃES, Sérgio Fonseca. "A Gestão da cooperação internacional do Inpa: diretrizes básicas para consolidação", em Gestão da Cooperação Internacional-experiências e depoimentos, Coletânea de ensaios dos participantes do IV Procint, FEA/ USP, Org. por Jacques Marcovitch e Maria Selma Baião, 1994.

MACHADO, Carlos José Saldanha. L'ORSTOM en action en Amazonie: décryptage et synthèese d'un dispositif de recherche. Communication au Colloque du Cinquentenaire de la création de l'ORSTOM à l'Unesco, 19-23 set. 1994.

MACHADO, Carlos José Saldanha. Formação e modo de organização de uma coletividade heterogênea de pesquisadores: o caso do Instituto Nacional de Pesquisas da Amazônia. Revista Internacional de Estudos Políticos 1(3), 1999, pp. 567-600.

MARCOVITCH, Jacques. "Competição, cooperação e competitividade”, em MARCOVITCH, Jacques (org.). Cooperação internacional-estratégia e gestão. São Paulo, Edusp, São Paulo, 1994. 
MCT. Portaria MCT no 55. Aprova o Regulamento sobre coleta, por estrangeiros, de dados e materiais científicos do Brasil. Diário Oficial da União, 14/3/1990.

MCT. Relatório Tundisi (Relatório Final da Comissão destinada a propor uma política de longo prazo para os institutos do MCT), 2001.

MCT/ INPA. Relatório Bevilácqua. O INPA Como Centro de Excelência em Pesquisas na Amazônia. Relatório da Comissão de Alto Nível, 1993.

NSF. Science and Engineering Indicators 2004, http://www.nsf.gov/sbe/srs/seind04/ start.htm.

SUDAM/ PNUD/GTZ. Simpósio Internacional sobre Cenários de Desenvolvimento Sustentado: Alternativas Econômicas e Perspectivas de Cooperação Internacional, 1992.

TONI, F. Avaliação da cooperação científica internacional em pesquisa biológica na Amazônia: o caso Brasil e França. Dissertação de Mestrado, Campinas, Unicamp, 1994.

TONI, Fabiano e VELHO, Léa. “A presença francesa no Instituto Nacional de Pesquisas da Amazônia - Inpa”. Interciencia, vol. 21, n. 1, jan.-fev. 1996.

TUNDISI, J. G. “Análise da auto-avaliação do Inpa”. Planejamento estratégico do INPA, Relatório. Manaus, Inpa, 1993.

VAL, Vera M. F. A. e HIGUCHI, Maria I. G. O Inpa no contexto da cooperação internacional. Manaus, Aspi/ Inpa, 1994.

VELHO, Léa. "Impactos dos projetos colaborativos Norte-Sul em ciências biológicas na Amazônia”. Artigo apresentado no seminário internacional Dinâmica y entorno de los grupos de investigacion, Bogotá, 19 a 20/5/1994.

VELHO, Léa e VELHO, Paulo. "Scientific Collaboration of Advanced/Developing Countries in Biological Sciences: The Case of The Maraca Rain Forest Project". Cadernos de Ciência \& Tecnologia, Brasília, vol. 13, n. 1, 1996, pp. 9-20.

WEIGEL, Peter. Ciência e desenvolvimento: dificuldades de diálogo na experiência do Inpa. Dissertação de Mestrado, Belém, Plades/ Naea/ UFPA, 1994, mimeo.

RESUMO - Apesar dos seus cinqüenta anos, foi somente na última década que começaram a vir a público diversos trabalhos abordando distintos aspectos que, direta ou indiretamente, tratam da cooperação científica internacional do Instituto Nacional de Pesquisas da Amazônia (Inpa, um dos institutos de pesquisa governamentais mais antigos da região, fundado em 1954. São dissertações, teses, artigos, monografias, pesquisas de opinião, avaliações, estudos, relatórios de comissões criadas pelo MCT e planos institucionais. De uma forma geral, esses trabalhos são bastante críticos; os problemas apontados, recorrentes; e as soluções propostas nunca implementadas. Este artigo é parte da busca de comprovação da hipótese de que a política de cooperação científica internacional na Amazônia sofreu uma inflexão com a edição do Dec. 98.830/90 e da Portaria do MCT que o regularizou (Portaria 55/90), editada no oltimo dia do governo Sarney (1985-1990).

Palavras-chave: Amazônia; Instituto Nacional de Pesquisas da Amazônia (Inpa); cooperação Internacional. 
ABSTRACT - Despite its 50 year, only in the last decade was presented to public some papers and works app.roaching, directly or indirectly, aspects related to international cooperation in Inpa, one of the older governmental research institute of the region, established in 1954. These works are dissertations, thesis, articles, monographs, public opinion poll, evaluations, studies, reports of commissions created by Science and Technology Department and institutional programs. Usually, these works are sufficiently critical; recurring showed problems; and proposed solutions never implemented. This article is one part of the search for evidences about the hypothesis that the international cooperation policy in Amazonia suffered an inflection with the edition of $98.830 / 90$ Decree and the by the regularization by Science and Technology Department (55/90 Decree), editedin the last day of the Sarney government (1985/1990).

Key-words: Amazon; Amazon National Research Institute; international cooperation.

William Gama, doutor em Política Científica e Tecnológica, é pesquisador do Instituto Nacional de Pesquisa da Amazônia (Inpa). @ - william@inpa.gov.br

Léa Velho é professora associada do Departamento de Política Científica e Tecnológica da Unicamp.

Texto recebido em 23/3/2005 e aceito em 18/4/2005. 